\title{
Memoria histórica e imaginación jurídica: políticas estéticas de la memoria, desde la justicia poética al forensic turn
}

\author{
Ulrich Winter \\ Universidad de Marburg
}

\section{Resumen:}

El propósito de este ensayo es indagar en las interrelaciones entre los distintos discursos narrativos de elaboración del pasado dictatorial, particularmente entre los no-fácticos estético, literario, cultural, etc.- y los fáctico-disciplinarios —el jurídico-legal y el historiográfico- La hipótesis de este ensayo es que los lenguajes de la historia, del derecho y de la cultura conforman una formación discursiva (Foucault) o interdiscurso de la memoria histórica, esto es, un modelo discursivo de segundo grado, basado en la conjunción de distintos discursos particulares y en base a una serie de analogías e interrelaciones. El ensayo analizará hasta qué punto la judicialización de la política corresponde a un proceso paralelo que podría llamarse judicialización del discurso estético o cultural. Este proceso forma parte del así llamado 'forensic turn' o 'giro forense'. En un sentido amplio, lo forense apunta al hecho de que todos los discursos reivindicativos sobre el pasado constituyen prácticas 'forenses', en la medida en que constituyen 'foros' de la justicia. Es también en este sentido que puede hablarse de un interdiscurso de la memoria. Se darán algunas pautas para analizar las analogías y transferencias entre discursos fácticos y discursos estéticos. En un primer paso se recuentan algunas interrelaciones entre los tres discursos sobre el pasado. Estas interrelaciones se explican por una serie de analogías intrínsecas o rasgos compartidos, entre otros, su carácter representativo (o epidíctico), narrativo, epistémico, demostrativo y reivindicativo. En contextos de justicia histórica, estas características son inseparables de su función ético-socialrestitutiva, retributiva y/o reparadora. En un tercer paso analizaremos algunos axiomas del giro forense, particularmente sus asunciones materialistas y poshumanas y su repercusión en el campo cultural.

Palabras clave: España, memoria histórica, giro forense, materialismo, cultura, literatura, historiografía

\begin{abstract}
:
The paper deals with how factual (historiographical and legal) and nonfactual (aesthetic, literary, cultural, etc.) discourses on the past intertwine. It starts from the hypothesis that the languages of history, law and culture form a discursive formation (Foucault). In the first part, the essay analyzes to which point the judicialization of politics is paralleled by an analogous process of judicialization of cultural and aesthetic discourses. These processes seem to be related to a more general turn in cultural studies, referred to as forensic turn. In the second part, the paper proposes a conceptualization of the interrelations between factual and non-factual narratives of the past. In the third part, the essay discusses some ideological presuppositions of the forensic turn, mainly its materialist and post-human assumptions, as well as its influence on the cultural field.
\end{abstract}

Keywords: Spain, historical memory, forensic turn, materialism, culture, literature, historiography 


\section{Introducción: La judicialización de las políticas estéticas de la memoria}

El propósito de este ensayo es indagar en las interrelaciones entre los distintos discursos narrativos de elaboración del pasado dictatorial, particularmente entre los no-fácticos —estético, literario, cultural, etc.—y los fáctico-disciplinarios —el jurídico-legal y el historiográfico- L La hipótesis de este ensayo es que los lenguajes de la historia, del derecho y de la cultura conforman una formación discursiva (Foucault 1969) o interdiscurso de la memoria histórica, esto es, un modelo discursivo de segundo grado, basado en la conjunción de distintos discursos particulares y en base a una serie de analogías e interrelaciones. ¿Cómo se efectúa la interrelación entre ellos? En contextos de pos-dictadura, como en España y el Cono Sur, es natural que los discursos fácticos sobre el pasado asuman una posición hegemónica, ya que se trata de la recuperación de una verdad histórica en el marco del proyecto de justicia transicional. En cambio, los discursos no fácticos de reivindicación de la justicia histórica, constituyen algo como la parte cultural de aquel proceso de elaboración del pasado violento. La literatura y el cine están igualmente comprometidos con los imperativos jurídico-historiográfico-éticos de recuperación de las verdades históricas, sin disponer por eso de la fuerza normativa propia de la justicia (y, en menor grado, de la historiografía). Desde luego, literatura y cine persiguen objetivos distintos. En la medida en que gestionan el imaginario del pasado representan una forma de imaginación jurídica y/o histórica. Los discursos fácticos, a su vez, se vuelven marcos epistemológicos para las producciones estéticas de la memoria, esto es, horizontes orientativos y directores. Es más, influyen en cuanto sistema argumentativo o productor de imágenes sugerentes — de forma consciente o inconsciente, directa o indirecta - en las producciones estéticas. Dicho de otra forma: Para cumplir con los imperativos de memoria histórica y formar parte del conjunto de los distintos lenguajes de elaboración del pasado, tal como quedan definidos por los valores ético-jurídicos de verdad y justicia, los relatos estéticos llevan a cabo una traducción o transferencia del sistema discursivo científico al sistema discursivo cultural o estético. Representan un proyecto de política estética destinado a producir otras "formas de verdad" (Martínez Rubio), en este caso literarias. La estrategia estética consiste a menudo en una operación que podría llamarse mimetismo o simulacro del lenguaje jurídico y/o historiográfico, sus procedimientos, sistemas argumentativos, estilos, etc. Un ejemplo es el uso de materiales documentales y hechos históricos como supuesta prueba o evidencia de la facticidad de lo narrado, de una "rhetoric of fact" (Young 140-180) o "retórica de la antiliterariedad" (Gómez López Quiñones 50-75; Winter, "Memoria recuperada") en literatura y cine, tal como sucede en la novela Soldados de Salamina (2001). El prestigio de los discursos fácticos sobre los estéticos lleva a la plausibilización de estos esquemas de argumentación en el relato de ficción. ${ }^{1}$ Como luego veremos, la necesidad de vincularse con verdades éticas y la afiliación al objetivo político de recuperar estas verdades, por ejemplo la justicia histórica, lleva a su vez a un cambio del concepto de lo estético. Lo estético, tradicionalmente relacionado con las artes y su contemplación, ya no se define tanto según esta línea de idealismo kantiano sino desde axiomas materialistas. Actualmente, el discurso jurídicolegal asume entre los discursos fácticos una función particular. En dos sentidos: (1) Si

\footnotetext{
${ }^{1}$ Por supuesto, esto vale también para relatos subversivos que cuestionan la versión oficial del pasado.
} 
bien es verdad que la transición democrática es un proceso en primer lugar de transformación política (y en segundo lugar social, cívico y cultural), la elaboración del pasado y la reivindicación de la verdad histórica la asumen cada vez más las instituciones jurídicas, nacionales e internacionales, en el sentido de una "judicialización de la política" (Sieder, Schjolden y Angell). Esto vale en cierto modo para la justicia transicional en las pos-dictaduras hispanoamericanas, sin embargo en el Estado español las instituciones jurídicas rehúsan llevar a cabo esta labor. ${ }^{2}$ (2) La reciente proclamación de un giro forense o forensic turn (Braidotti) es la prueba más evidente de la hegemonización del discurso jurídico. En un sentido específico, el forensic turn se refiere al papel primordial, dentro de la lucha por la memoria, de las ciencias forenses implicadas en la exhumación de fosas comunes de la Guerra Civil y de la dictadura (Ferrándiz, Robben y Wilson). Pero como pasa muchas veces, las realidades y prácticas relacionadas con una determinada constelación histórico-cultural tienen al mismo tiempo valor metafórico o sintomático. La exhumación de las fosas es, a su vez, consecuencia de la evolución transnacional de la justicia transicional y, al mismo tiempo, práctica emblemática de la hegemonización del discurso forense-jurídico en cuanto dispositivo de verdad histórica.

En una acepción más amplia, el término 'forense' incluye también los relatos culturales, estéticos, comprometidos con la verdad histórica, tanto más cuanto se orientan hacia los discursos fácticos. En este sentido amplio, lo forense apunta al hecho de que todos los discursos reivindicativos sobre el pasado constituyen prácticas 'forenses', en la medida en que constituyen 'foros' de la justicia, según el sentido etimológico de la palabra forum o ágora (Weizman 9). Es también en este sentido que puede hablarse de un interdiscurso de la memoria. El propósito de este ensayo es analizar hasta qué punto la judicialización de la política corresponde a un proceso paralelo que podría llamarse judicialización del discurso estético o cultural. En lo que sigue, se darán algunas pautas para analizar las analogías y transferencias entre discursos fácticos y discursos estéticos. Dada la predominancia del discurso jurídico me centraré más en este. En un primer paso se recuentan algunas interrelaciones entre los tres discursos sobre el pasado. Estas interrelaciones se explican por una serie de analogías intrínsecas o rasgos compartidos, entre otros, su carácter representativo (o epidíctico), narrativo, epistémico, demostrativo y reivindicativo. En contextos de justicia histórica, estas características son inseparables de su función ético-social-restitutiva, retributiva y/o reparadora. En un tercer paso analizaremos algunos axiomas del giro forense, particularmente sus asunciones materialistas y poshumanas y su repercusión en el campo cultural. Como el objetivo principal del ensayo son los discursos estéticos y no los fácticos en sí, abordaremos los encuentros aproximativos entre ambos, ya de por sí encuentros interdisciplinares, desde una perspectiva cultural. No se trata, pues, de analizar la historiografía o la jurisprudencia como ciencia y sistema ni de sus gestiones institucionales o académicas, sino como un conjunto de formas y figuras, estilos, prácticas simbólicas, recursos, valores y objetivos que tienen impactos en el campo cultural.

\footnotetext{
${ }^{2}$ No obstante, Santos Juliá se lamenta de una “judicialización” de la historia (15), en el caso español.
} 


\section{Interrelaciones y puntos en común}

\section{Justicia poética/justicia histórica}

Históricamente, la interrelación entre literatura y derecho se condensa en el topos ilustrado de la poetic justice. Aunque esta noción data tan solo del siglo XVIII, se refiere a una interrelación endémica y elemental entre ambos discursos. Contar historias implica hacer juicios éticos sobre los actos realizados. Toda narración implica necesariamente posturas éticas (Ricoeur 142). La justicia poética se presenta en primer lugar como una configuración narrativa: acto o crimen cometido, investigación/averiguación, castigo/juicio/reparación. En cuanto tal, cuenta con un característico régimen temporal que vincula pasado y presente de forma no puramente cronológica. La temporalidad de la justicia poética se caracteriza por la paradoja de corregir y por lo tanto cambiar algo que en un principio es inalterable e intangible: el pasado (Kertzer). No es por casualidad que una de las modalidades más difundidas de la novela de la memoria es la trama de indagación en el pasado, ya sea por parte de una persona interesada que explora la historia familiar, un periodista, un detective privado, etc. La incursión en el pasado y la averiguación de actos perpetrados corresponde, paso por paso, a una repetición intelectual del pasado, a su corrección. El ejercicio de la justicia (por ejemplo, mediante un castigo o el simple acto de hacer público un crimen al contarlo, etc.) se calca sobre la configuración temporal propia de la justicia poética. Se trata, eso sí, en el caso de la trama de la investigación, de una repetición y corrección imaginaria o simbólica del pasado, pero de ninguna manera irreal. En contextos de justicia transicional, la justicia poética es demanda de justicia histórica. La correción consiste precisamente en el hecho de hacer pública una historia no narrada, de presentarla al foro, lo que corresponde al sentido amplio de lo forense. Este modelo narrativo se encuentra en producciones tan distintas como las novelas de memoria de Antonio Muñoz Molina (Beatus ille, 1986, El jinete polaco, 1991), de Javier Cercas (Soldados de Salamina, 2001), de Isaac Rosa (El vano ayer, 2004) o, en Hispanoamérica, las novelas neopoliciales de Díaz Eterovich. $^{3}$

La estructura temporal del relato de investigación no solo reproduce la temporalidad de la justicia poética, como hemos visto, sino que ambos corresponden también al marco temporal inherente a un determinado concepto de historia o de justicia histórica. Hasta cierto punto, la justicia poética y la justicia histórica comparten el mismo régimen temporal. La razón es que también la demanda de justicia histórica implica la idea de una corrección del pasado, una repetición que, al igual que en el caso de la justicia poética, no debería limitarse a lo simbólico. O se limitaría a lo simbólico si se adaptase el punto de vista de lo que Walter Benjamin llama, en sus "Tesis sobre el concepto de Historia", el "historicismo" (Benjamin, Gesammelte Schriften 1, 695). Segun el historicismo, el pasado es pasado, porque uno no puede deshacer lo hecho. Pero de ser así, la reivindicación de la justicia histórica no tendría sentido. Desde el punto de vista del "materialismo histórico" (695), en cambio, el hacer memoria o justicia supone

\footnotetext{
${ }^{3}$ Para un análisis de la novela negra chilena, comprometida en la elaboración del pasado desde esta perspectiva del forensic turn, véase Winter, "Corpus delicti”.

${ }^{4}$ Para una traducción de las "Tesis" en castellano, véase Mate.
} 
una inversión temporal. Es entonces cuando el presente se "ilumina" desde el pasado y se produce una "imagen dialéctica": "lo que ha sido se une como un relámpago al ahora en una constelación" (Benjamin, Pasajes 465). La repetición correctiva (o retributiva) del pasado consiste en una relectura de la Historia bajo el signo de la Justicia. ${ }^{5}$

\section{"La Historia universal es el juicio universal"}

No solo la Literatura está desde siempre estrechamente enlazada con el derecho, también lo están, de forma histórica, sistemática e ideológica, el derecho y la historia, las productoras disciplinarias de relatos sobre el pasado más potentes y dotadas de más fuerza normativa. Como apuntó Carlo Ginzburg (1991), la principal labor tanto del historiador como del juez consiste en atribuir/imputar determinados actos a determinados sujetos. Ambos se valen de procedimientos y métodos argumentativos y retóricos parecidos. Históricamente, ambos oficios se han valido de dos operaciones discursivas idénticas, explicar y comprender. La emergencia más o menos simultánea de la historiografía y jurisdicción modernas en el siglo XIX se basa en parte en una parcial identificación mutua, en cuanto instancias que pretenden explicar - $-\mathrm{y}$ asentar- el curso de la historia, o su sentido, respectivamente, según el famoso dicho de Schiller, luego retomado por Hegel en su Filosofía del Derecho, de que "la Historia universal es el Juicio universal" ("Die Weltgeschichte ist das Weltgericht"). En el siglo XX, la historiografía experimentó varios giros paradigmáticos orientándose cada vez más a la comprensión, y menos a la explicación, incluida la reflexión de sus propios quehaceres. En vez de limitarse a los actos y los acontecimientos se orienta hacia los contextos e imaginarios que han posibilitado los actos. De ahí también resulta el estatus, muy distinto en ambos, del error y de lo probable (pero todavía no demostrado o no susceptible de demostración alguna), y, por lo tanto, el estatus de la imaginación, en cuanto operación productiva. Mientras que el Derecho precisa de pruebas, documentación, y fracasa cuando se equivoca, para la historiografía, el error y lo probable (o sea, lo verosímil pero no demostrado) puede resultar productivo, hasta cierto punto, y esto tanto más cuanto prescinde de la pretensión decimonónica del universalismo y del poder hegemónico de explicación (Izquierdo Martín y Sánchez León). En cambio, lo que ambas disciplinas comparten es el hecho de que cada una produce su relato sobre el pasado mediante la co-producción de las fuentes a las cuales luego recurre: el levantar pruebas, recolectar fuentes y otras formas de establecer un archivo que luego sirve de base para los discursos factuales sobre el pasado.

\footnotetext{
${ }^{5}$ En el sentido clásico, esta segunda lectura del pasado representa una lectura idealizada de la realidad histórica que remite a la diferencia entre poesía e historia tal como queda establecida por Aristoteles en su Ars poetica. Según el filósofo griego, no corresponde al poeta decir lo que (supuestamente) ha sucedido, sino lo que podría suceder, esto es, lo posible según las leyes de la verosimilitud o la necesidad. La diferencia entre el historiador y el poeta está en que el primero dice lo que ha sucedido, y el segundo, lo que podría suceder. En el sentido benjaminiano, esta relectura sería una lectura utópica o hasta profética, lo que la distingue de la temporalidad circular del trauma. Por supuesto, la corrección del pasado no puede ser una reparación material, pero, eso sí, una corrección proporcional en el sentido de la justicia retributiva.
} 


\section{El juez, el historiador y el ciudadano}

¿Cómo entran los relatos estéticos en este esquema?, ¿y cuál sería su contribución? En su libro La mémoire, l'bistoire, l'oubli, Paul Ricœur (2000) reexamina las relaciones entre derecho e historia y llega a la conclusión, entre otras, de que en materia de memoria hay que añadir, al lado del juez y el historiador, una tercera instancia: el ciudadano implicado en la lucha por la memoria, ya sea de forma militante o como escritor o intelectual. Desde esta función social la primera tarea del escritor-ciudadano sería la de gestionar el imaginario del pasado. Entre los distintos discursos, ciencias y dispositivos sociales destinados a la elaboración del pasado, las producciones culturales asumen, en cuanto políticas estéticas, la labor de encarar el pasado y sus sombras en el presente desde lo afectivo, íntimo y privado, y son predilectas para el registro de lo traumático. En cuanto narrativa, los relatos desarrollan funciones terapéuticas (para las víctimas y los victimarios), pedagógicas (el conocimiento del pasado), testimoniales y políticas; a estas funciones se añade, en el contexto de la justicia poética y el giro forense, el compromiso ético. Por otra parte, en democracia cumplen un papel particular de punto de intersección entre las disciplinas, asumiendo el impulso o complementando la labor de la historiografía, de las ciencias sociales o incluso la jurisdicción.

\section{Derecho, historia y literatura como discursos narrativos, epistémicos y demos- trativos}

¿Cómo se explica la relación estrecha entre Derecho, Historia y Literatura? La posibilidad de transferencias entre discurso jurídico, historiográfico y literario se debe, en primer lugar, a una serie de analogías. Los tres representan, antes que nada, distintos tipos de relato; sus propuestas discursivas sobre el pasado se montan sobre figuras y tropos retóricos (J.B. White; H. White; Weisberg; Ward). Como es bien sabido, tampoco el discurso legal está exento de imaginación jurídica, y en las salas de audiencia de las instituciones legales no faltan puestas en escena estéticas. ${ }^{6}$ No solo la novela y el cine son relatos de la memoria, también lo son la historiografía y la jurisdicción. No es por casualidad que la retórica antigua distinguiera (y por tanto relacionara) las modalidades representativo-epidíctica y demostrativo-forense como dos tipos fundamentales de discurso (Quintiliano y Aristóteles). Así que, en un sentido muy fundamental, podríamos decir que la figura retórica de la prosopopeia, o sea, el prestar o dar voz a los sin voz, el arte de hacer hablar a los muertos, dándoles una voz, ${ }^{7}$ esta figura de discurso constituye tal vez el gesto compartido más profundo y universal de los discursos historiográfico, forense y estético sobre el pasado. Ya sean los muertos y las víctimas cuyas historias hayan quedado indocumentadas, desconocidas o no valorizadas, ya sean los sin voz en sentido tan solo aparentemente metafórico, los restos materiales de actos de violencia, que se presentan al tribunal o se conjuran en las obras de ficción. Las interferencias entre los tres discursos se explican por su condición narrativa, epistemo-

\footnotetext{
${ }^{6}$ Véase, por ejemplo, el documental Nazi Concentration Camps, cuyas imágenes luego se utilizaron como testimonio y pruebas en los procesos de Nuremberg contra el nazismo (Baer) o la construcción de las imágenes difundidas de los juicios contra la dictadura argentina (Feld).

${ }^{7}$ Weizman propone esta figura como impulso original para su proyecto de forensic arquitecture.
} 
lógica y, en contextos de deuda histórica para con el pasado, ético-restitutiva. Es precisamente el gesto reivindicativo frente a un pasado silenciado y la consiguiente búsqueda de evidencia de injusticias que convierte la justicia legal y las producciones culturales en discursos epistémicos y demostrativos sobre el pasado.

El discurso literario de la memoria es una práctica ético-performativa en la medida en que constituye un gesto de reivindicación, de recuperación, de reconciliación, de perdón o de resistencia; y es una práctica simbólica en cuanto representación imaginaria del pasado. Lo fáctico (los discursos fácticos) representan su doble horizonte de referencia: en cuanto representación imaginaria del pasado, la literatura de la memoria apunta a la verdad histórica absoluta, y en cuanto acto ético, los discursos estéticos apuntan a la justicia absoluta. Verdad histórica y justicia - he aquí el grado cero y virtualmente inalcanzable de veracidad de la novela de la memoria-. Hasta cierto punto, la cultura de la memoria constituye una arena para la puesta en escena permanente del encuentro aproximativo entre estos horizontes de veridicción (o parrhesia, en el sentido de Foucault, Discours). Aquí cabe recordar otra vez el concepto de historia de Walter Benjamin, al cual se aludió antes. Para el filósofo alemán, ambas realidades del pasado, la fáctica (historia) y la ética (justicia), no son más que una sola: la cuestión de la justicia — y de su falta, la injusticia — más que una faceta, es una dimensión integrante, ontológica, del pasado. ${ }^{8}$ Según el materialismo histórico benjaminiano, la historiografía es un discurso cuasi-jurídico, de reconocimiento y restitución. Y la cultura de la memoria alcanza su plena razón de ser al convertirse en jurisdicción e historiografía imaginaria. En este sentido, literatura, historia y derecho forman, pues, un triángulo de discursos, un interdiscurso, que hay que tener en cuenta a la hora de dilucidar el posible sentido de la 'justicia histórica' en textos estéticos.

\section{La literatura como imaginación jurídica e histórica}

De ahí se explica el mimetismo, mencionado al principio de este ensayo, de los discursos hegemónicos sobre el pasado por parte de los relatos estéticos, por ejemplo, la "retórica de la antiliterariedad". Dada la hegemonía discursiva de los relatos fácticos sobre el pasado, este mimetismo se efectúa en muchos casos, aunque no exclusivamente, en esta dirección y no en la otra. Sus formas son múltiples. Los distintos géneros estéticos de la memoria representan en este sentido distintas configuraciones para

\footnotetext{
${ }^{8}$ En las Tesis sobre la filosofía de la historia, Benjamin distingue entre la idea de historia como tradición de lo escrito y la idea de historia como pasado silenciado por esta tradición (i.e. la historiografía oficial); entre lo que ha sido porque se conservó en el relato y lo que pudo ser pero no se plasmó en ningún relato o no llegó a incorporarse a la historiografía oficial, pero, precisamente por eso, cuestiona la legitimidad de lo que se considera como fáctico. Es en base a esta diferencia que Benjamin distingue entre historicismo y materialismo histórico. Como ya señalé, el historicismo busca conocer el pasado "como verdaderamente ha sido" ("wie es denn eigentlich gewesen ist") (Benjamin, Gesammelte Schriften 1, 695), en palabras del fundador del historicismo, Leopold von Ranke. Concibe la relación entre pasado y presente como un continuum de historia, y de historias, esto es, de modo fundamentalmente narrativo y temporal. Frente a este concepto del pasado como pasado, el materialismo histórico, en cambio, es producto de la "recordación" (Mate 121) ("Eingedenken") (Benjamin, Gesammelte Schriften 1, 701-702) La "recordación" del pasado es al mismo tiempo la recordación de esta tensión temporal. Injusticia y olvido, el olvido como injusticia historiográfica, convierten el propio pasado en un caso pendiente, dotándole de una carga de futuro, de una fuerza mesiánica para su retorno en el presente. Por tanto, la diferencia entre pasado y justicia queda prácticamente anulada.
} 
determinadas políticas estéticas. Por ejemplo, el documental, que al valerse de recursos tanto estéticos como historiográficos, se acerca al máximo a la verdad histórica haciendo al mismo tiempo mimetismo de discursos jurídicos (en caso de falta de jurisdicción, como veremos en el caso de Montse Armengou, véase abajo), o novelas como La voz dormida de Dulce Chacón que, al acercarse al máximo al documental, abogan por el derecho de los colectivos de víctimas. En otros casos, la repercusión de lo jurídico e historiográfico en textos estéticos ocurre de forma mucho más indirecta y abstracta: por ejemplo, cuando la trama se monta sobre la investigación de casos o enigmas históricos, de verdades históricas silenciadas como en la novela Les Veus del Pamano (2004), de Jaume Cabré. Dada la pretensión ético-reivindicativa, por un lado, y el mimetismo de discursos fácticos, por otro, virtualmente todas las estructuras narrativas de los relatos estéticos se prestan a una lectura no solo como imaginación histórica sino también como imaginación jurídica, esto es, son susceptibles de traducirse en configuraciones o propuestas jurídicas más o menos implícitas o explícitas: desde la estructura de la trama hasta la perspectiva narrativa y la consiguiente construcción del lector implícito, al cual puede asignarse un papel más o menos comprometido, de testigo, de colaborador, de oyente empático, de juez, de historiador o de recolector de testimonios, de jurado, que a lo largo de la novela o el filme, se forma su idea del caso en cuestión.

\section{Derecho, historia y cultura de la memoria como discursos sociales}

A pesar de la hegemonía del discurso jurídico, la interrelación entre los discursos fáctico-disciplinarios y los no-fáctico-estéticos no es una calle de sentido único. Esto se ve cuando miramos el triángulo de discursos sobre el pasado desde un punto de vista no tanto sistemático, filosófico o teórico, sino como dispositivo social, y en contextos concretos. No solo influye la historiografía y la jurisidicción en prácticas estéticas, sino también al revés. En vez de monolítico, el discurso legal es:

intersection of private memory and public history, a site of recurring and converging personal and collective trauma. Law lives in images that saturate our culture and have a power of their own as the moving image provides a domain in which legal power operates independently of law's formal institutions. (Kamir 38)

Lo que dice la jurista israelí-americana sobre las imágenes del cine es aplicable también al relato. Esto implica la posibilidad de una lectura cultural del derecho o de la gestión judicial como interacción cultural, social y política, por parte de los mismos actores de la Justicia. El caso más emblemático, a este respecto, es tal vez el de Baltasar Garzón. Para el ex juez instructor de la Audiencia Nacional española, la jurisdicción no es un discurso monológico limitado a la ejecución de la ley, sino que forma parte de toda una estrategia político-social. Según Rothenberg (2001), el derecho para Garzón es, antes que nada, un arma contra la violencia política y tan solo indirectamente contra la injusticia en sí. El juez se deja guiar no tanto por los conceptos abstractos de justicia jurídica, sino por las necesidades políticas del momento, lo que permite la interpretación dinámica y flexible de conceptos en general estáticos y bien definidos como por ejemplo el de 'genocidio', en cuanto conceptos 'vivos' y por lo tanto aplicables a una gama más 
amplia de casos de violencia del Estado. Esta lectura eminentemente cultural y abierta de la gestión jurídica corresponde a la naturaleza inestable y social de la propia memoria y por lo tanto es susceptible de integrar los demás discursos sociales de memoria.

\section{Cine y literatura como jurisdicción alternativa y anticipativa}

En épocas de justicia transicional, cine y literatura pueden actuar de jurisdicción alternativa o incluso anticipativa. Es el propio estatus de ficción el que convierte literatura y cine de la memoria en un ejercicio de "training audiences in judgement while examinig legal norms and critiquing legal systems by exposing its underlying value systems". (Kamir 28) Al margen de su valor estético o de divertimiento, constituyen un ejercicio de renegociación implícita o explícita de discursos éticos y legales, de cuestionamiento de la validez social de las normas jurídicas, o sea, de lo que se ha dado en llamar "the social life of rights" (Wilson y Mitchell). Esto vale también para la relación entre historia y literatura. En épocas de justicia transicional, esto es, de falta (provisional o a largo plazo) de un sistema jurídico eficaz, la literatura y el cine llegan a ser no solo un discurso que influye sobre la Justicia, o sea, "laboratorio y campo de entrenamiento de valores jurídicos" (véase cita arriba) sino jurisdicción faute de mieux. Que un documental o una novela se vuelva en jurisdicción suplementaria, o de Ersatz, depende del grado de funcionamiento o de disfunción del sistema legal, y, por lo tanto, del mismo momento histórico. Por lo tanto, para analizar cómo la hegemonización del discurso jurídico estructura también distintas políticas estéticas de la memoria hay que tener en cuenta los márgenes de maniobra y el prestigio de las instituciones legales en los estados pos-dictatoriales. La agencia de la política y de la justicia en tiempos de justicia transicional difiere en distintos ámbitos pos-dictatoriales. Es probable, por lo tanto, que la relación entre lo jurídico y lo estético difiera también en los distintos espacios culturales. En el Estado español, la relación Derecho/Memoria está altamente politizada y polemizada, si miramos los intentos fracasados y cuestionables de reglamentar la memoria colectiva por ley, como en el caso de la Ley de Amnistía de 1977, la Ley de Memoria Histórica de 2007 o el juicio y la sentencia del juez Baltasar Garzón a finales de 2011, y, al mismo tiempo, la ausencia, hasta el día de hoy, de una comisión de verdad. En el ámbito cultural, por lo tanto, los relatos no-fácticos reclaman de una forma u otra la justicia histórica, y ejercen, a su vez, justicia faute de mieux, adoptando al mismo tiempo una interpretación cuasi-legal de la realidad. Montse Armengou, periodista catalana especializada en documentales de investigación, considera sus documentales sobre crímenes del franquismo como herramientas reparadoras "ya que no hemos tenido la justicia de los tribunales" (Herrmann 220). Cabe señalar que estos intentos informales de reivindicación de justicia reparadora valen la pena incluso cuando finalmente no desembocan en autos de procesamiento, en justicia retributiva, sentencia y legislación. La condena moral es un valor en sí y puede ser un objetivo válido tanto para las políticas estéticas como para los propios actores jurídicos. En relación a la actuación de la Audiencia Nacional española en el caso de los crímenes contra la humanidad cometidos en Argentina y Chile, el jurista Casteos Abad afirma que en los primeros años de posdictadura 
moral condemnation has long been a central and often successful strategy of advocates. Not even the complainants imagined that the case would lead to material justice through the Spanish state $[\ldots]$ But a judicial ruling would constitute a genuine victory $[\ldots]$ in its high symbolic value, in its significance as a moral judgement. (cit. en Rothenberg 930)

Es entonces cuando la literatura y el cine adquieren su plena dimensión forense, que es, en un sentido etimológico y fundamental, el 'hacer público', o llevarlo al forum. O en palabras de Montse Armengou, cuyos documentales "han sido el espacio donde por primera vez $[. .$.$] muchas víctimas han podido explicar ante un auditorio amplio - los$ hechos que [les] sucedieron" (Armengou 61).

La reivindicación informal —estética - de justicia reparadora no se limita, por supuesto, a las transiciones democráticas. En la época franquista, la poesía social se consideraba "un arma cargada de futuro"(Celaya) — fórmula que no carece de significado jurídico (es una apelación camuflada al derecho al tiranicidio)—. Los neorrealistas, según Juan Goytisolo, se veían a sí mismos como cámaras de vigilancia —y por lo tanto herramienta historiográfica y demostrativa en sentido jurídico- que captan y registran, por su parte, la verdadera realidad de la represión en la vida cotidiana, más allá de las deformaciones propagandísticas del estado policial franquista. En la transición democrática fueron los periódicos los que primero asumieron este papel, y luego la historiografía, la novela y el cine. Mientras que una parte de estas producciones culturales - supuestamente los que más se prestan a las leyes de mercado y los objetivos económicos de las editoriales - se limitan a reivindicar una vaga idea de justicia poética, otros, por su capacidad aglutinadora, son capaces de provocar lo que Sebastiaan Faber llama "actos afiliativos" por parte de sus lectores, esto es, la capacidad de leer discursos estéticos como propuestas forenses. Las producciones culturales de la memoria, al margen de compensar los defectos y deficits del sistema legal, pueden llegar a convertirse en un dispositivo de reflexión y elemento correctivo de valores y normas jurídicos, de actitudes y creencias vigentes sobre lo que es justicia, lo que a la larga puede tener efectos sobre el propio sistema jurídico.

\section{El forensic turn y la estética materialista}

En España, el escenario más emblemático — diríase la escena primaria - para el interdiscurso de la memoria bajo el signo de lo forense son las prácticas y relatos alrededor de la exhumación de las fosas comunes de la Guerra Civil y la Dictadura. Que la reaparición de los restos humanos en las fosas se haya convertido no solo en realidad necesaria y doliente sino también en uno de los símbolos más potentes de las atrocidades del pasado se debe precisamente a esta razón. El antropólogo Francisco Ferrándiz insiste precisamente en este hecho interdisciplinario:

The mass graves make available concrete data while providing an emerging context for the telling of narratives of defeat, which elicit many different types of discourse and performances, ranging from on-site technical accounts by forensic scientists to emotionally explosive gestures on the part of the relatives. (Ferrándiz 5-6)

La exhumación reúne forenses, profesionales, juristas y artistas alrededor de los restos materiales de la guerra y la represión. Los especialistas y profesionales se dedican al 
trabajo común de esclarecimiento de las atrocidades de la guerra, valiéndose cada uno de sus métodos. Desde una perspectiva cultural, este trabajo transdisciplinar, así como el discurso que se genera alrededor de la memoria, cuentan implícitamente con toda una serie de teoremas culturales —entre otras, la Actor-Network-Theory latouriana (Latour) y los ideologemas del llamado material o post-human turn en las Humanidades (Braidotti) - de las cuales se derivan una serie de premisas: la primera es que no son tanto (o no solo) las víctimas humanas (vivas) las que hablan del pasado, sino también - y en primer lugar- los restos materiales de los actos atroces que es preciso 'hacer hablar'. Segundo, que estos restos humanos no se consideran simplemente como objetos representables del pasado violento, sino que los restos mismos constituyen co-agentes en la cadena de interpretación del pasado. Por un lado, porque no se limitan a ser desencadenantes pasivos de los relatos; en la cita de Ferrándiz, la fosa parece disponer de agencia propia, se representa como actor activo que impulsa y provoca la producción de relatos e imágenes. Los huesos y los objetos encontrados en las fosas constituyen no solo sismogramas de los hechos, sino que son registro y sujeto estético en sí. Estético en un sentido materialista, y menos idealista. ${ }^{9}$ Por esta razón, el trabajo forense de la memoria requiere además de forenses y antropólogos, también cineastas, fotógrafos, dramaturgos y demás profesionales artísticos especializados en la percepción de la dimensión estética del testimonio de los restos materiales. Un ejemplo es el libro Oscura es la babitación donde dormimos, del fotógrafo Francesc Torres. El libro es una propuesta de documentación de la exhumación de los restos humanos de una fosa común en Villamayor de los Montes en 2004. Parte del concepto estético-político del libro es la conjunción de documentos arqueológicos, jurídicos y estéticos, de historia del arte y de testimonios. El libro en su conjunto es la plataforma de una propuesta interdisciplinaria y forense, en este sentido amplio. No solo la fotografía, sino también la literatura ha ido asumiendo el papel de traductor de las realidades de las fosas en narrativas, relatos, lugares de la memoria y sugerentes imágenes poéticas o "dialécticas" (Benjamin, Gesammelte Schriften V.1, 576). Cabe señalar que la producción de las correspondientes imágenes poéticas en literatura parte de una susceptibilidad estética estrechamente ligada con el material turn. En la novela On dormen les estrelles (2005) de Joan Garí, por ejemplo, el protagonista, antiguo combatiente republicano, ya anciano, catedrático y poeta renombrado, deja convencerse por un grupo de jóvenes para comprometerse con una asociación organizada por ellos para la recuperación de la memoria histórica en Valencia, inspirado y relacionado estrechamente con el conflicto del cementerio general en relación a las exhumaciones de restos óseos. Pero el giro materialista no se limita a repercusiones temáticas. En El vano ayer (2004) de Isaac Rosa es la bala encontrada en estas fosas la que constituye la "imagen dialéctica" benjaminiana en la medida en que representa, o mejor dicho, cosifica, la idea de la transversalidad temporal de las imágenes dialécticas:

[...] cientos de hombres fueron encajados [...] en una fosa común que cubrieron con cal y en la que después de tantos años se habrá desintegrado la carne y sólo quedarán las balas, los proyectiles abandonados, eso pedazo de plomo que permanece caliente, fijo en su trayectoria, entre la cal solidificada. (Rosa 248)

\footnotetext{
${ }^{9}$ Muy parecido a lo que Whitehead (18) llama "prehension” o conciencia/registro no-sensual.
} 
La bala es el resto histórico, al cual la novela 'forense' hace hablar, convirtiéndola en testigo material. Por cierto, este mismo simbolismo-materialismo de la bala se encuentra en muchas de las fotografías de Francesc Torres, reproducidos en el libro mencionado. Lo que indica las asunciones del giro materialista en estas representaciones es el hecho de que lo primordial no es el simbolismo en sí de los restos del pasado, esto es, el hecho de que los huesos humanos o la bala 'representen' el acontecimiento trágico en cuestión o se convierten en sus símbolos poéticos, sino la forma en la que los objetos encarnan la carga de actualización del pasado.

Como se ha visto - y con esto volvemos a las tesis expuestas al principio de este ensayo- la división de trabajo entre sistema legal, literatura y historiografía respecto a la objetivación de la memoria, es decir, a su transformación en historia y su integración en la imagen que tenemos del pasado, y a la larga, a la restitución de la justicia, constituye ya en sí un caso de interdisciplinariedad social, de interdisciplinariedad constitutiva para cualquier trabajo sobre la memoria. Por lo tanto, la emergencia de nuevos paradigmas como el giro forense afecta al interdiscurso de la memoria a varios niveles, y tanto más cuanto este giro proviene del discurso hegemónico, el jurídico, y repercute en el campo más susceptible de asumir estos impulsos, el discurso cultural.

\section{Bibliografía}

Armengou, Montse. "El documental de investigación como herramienta de reparación de las víctimas." Viento Sur 132 (2014): 58-63.

Baer, Ulrich (Ed.). Niemand zengt für den Zeugen. Erinnerungskultur nach der Shoah. Frankfurt am Main: Suhrkamp, 2000.

Benjamin, Walter. Gesammelte Schriften, t. 1. Ed. Rolf Tiedemann y Hermann Schweppenhäuser. Frankfurt am Main: Suhrkamp, 1974.

Benjamin, Walter. Gesammelte Schriften, t. 1. Ed. Rolf Tiedemann y Hermann Schweppenhäuser. Frankfurt am Main: Suhrkamp, 1982.

Benjamin, Walter. El libro de los pasajes. Madrid: Akal, 2005.

Braidotti, Rosi. The Posthuman. Cambridge et al.: The Polity Press, 2013.

Cabré, Jaume. Les Veus del Pamano, Barcelona: Proa, 2004.

Celaya, Gabriel. Cantos iberos. Alicante: Verbo, 1955.

Faber, Sebastiaan. "La literatura como acto afiliativo. La nueva novela de la Guerra Civil (2000-2007)." Contornos de la narrativa española actual (2000-2010). Un diálogo entre creadores y críticos. Ed. Paloma Álvarez-Blanco y Toni Dorca. Madrid/Frankfurt am Main: Iberoamericana/Vervuert, 2010. 101-110.

Feld, Claudia. Del estrado a la pantalla. Las imágenes del juicio a los ex comandantes en Argentina. Madrid: Siglo Veintiuno de España, 2002.

Ferrándiz, Francisco. "Cries and Whispers: Exhuming and Narrating Defeat in Spain Today.” Journal of Spanish Cultural Studies 9.2 (2008): 177-192. 
Ferrándiz, Francisco, Antonius C.G.M. Robben, Richard A. Wilson (Ed.). Necropolitics. Mass Graves and Exhumations in the Age of Human Rights. Philadelphia: The University of Pennsylvania Press, 2014.

Foucault, Michel. L'archéologie du savoir. Paris: Gallimard, 1969.

Foucault, Michel. Discours et vérité. Précédé de 'La parrêsia'. Ed. Henri-Paul Fruchaud y Daniele Lorenzini. Paris: Vrin, 2016.

Ginzburg, Carlo. Il gindice e lo storico. Considerazioni in margine al processo Sofri. Torino: Einaudi, 1991.

Gómez López-Quiñones, Antonio. La guerra persistente. Memoria, violencia y utopia: representaciones contemporáneas de la Guerra Civil. Frankfurt am Main/Madrid: Vervuert/Iberoamericana, 2006.

Herrmann, Gina. "Entrevista con Montse Armengou." Journal of Spanish Cultural Studies 9.2 (2008): 213-223.

Izquierdo Martín, Jesús y Pablo Sánchez León. "Lejana proximidad. Antropologías de la Guerra Civil Española.” Historia del Presente 7 (2006): 101-126.

Juliá, Santos. "Presentación”. Memoria de la guerra y del franquismo. Ed. Santos Juliá. Madrid: Taurus, 2006.

Kamir, Orit. "Cinematic Judgement and Jurisprudence: A Woman's Memory, Recovery, and Justice in a Post-Traumatic Society (A Study of Polanski's Death and the Maiden)." Law on the Screen. Ed. Austin Sarat, Lawrence Douglas y Martha Merrill Umphrey. Stanford: Stanford University Press, 2005. 27-81.

Kertzer, Jonathan. Poetic Justice and Legal Fictions. Cambridge: Cambridge University Press, 2010.

Latour, Bruno. "On actor-network theory. A few clarifications plus more than a few complications." Soziale Welt 47 (1996): 369-381.

Martínez Rubio, José. Las formas de la verdad. Investigación, docuficción y memoria en la novela bispánica (2000-2015). Barcelona: Anthropos, 2015.

Mate, Reyes. Medianoche en la historia. Comentarios a las tesis de Walter Benjamin 'Sobre el concepto de historia'. Madrid: Trotta, 2006.

Ricœur, Paul. La mémoire, l'histoire, l'oubli. Paris: Seuil, 2000.

Rosa, Isaac. El vano ayer. Barcelona: Seix Barral, 2004.

Rothenberg, Michael. “'Let Justice Judge’: An Interview with Judge Baltasar Garzón and Analysis of His Ideas." Human Rights Quarterly 24 (2001): 924-973.

Sieder, Rachel, Line Schjolden, Alan Angell (Ed.). The Judicialization of Politics in LatinAmerica. New York et al.: Palgrave MacMillan, 2005.

Torres, Francesc. Dark is the room where we sleep. Oscura es la babitacion donde dormimos. Barcelona/New York: Actar Editorial, 2007.

Ward, Ian. Law and Literature. Possibilities and Perspectives. Cambridge: Cambridge University Press, 1995. 
Weisberg, Richard H. Poethics, and other Strategies of Law and Literature. New York/Oxford: Columbia University Press, 1992.

Weizman, Eyal. Forensic Architecture: Notes from Fields and Forums/Forensische Architektur, Notizen von Feldern und Foren. Ostfildern: Hatje Cantz Verlag, 2012.

White, Hayden. Metahistory. The Historical Imagination in Nineteenth-Century Europe. Baltimore: Johns Hopkins University Press, 1974.

White, James Boyd. The Legal Imagination: Studies in the Nature of Legal Thought and Expression. Boston: Little/Brown, 1973.

Whitehead, Alfred North. Process and Reality. Corrected Version. Ed. David R. Griffin y Donald W. Sherburne. New York: The Free Press, [1929] 1978.

Wilson, Richard A. y Jon P. Mitchell,. "Introduction: The Social Life of Rights." Human Rights in Global Perspective. Anthropological Studies of Rights, Claims and Entitlements. Ed. Richard A. Wilson y Jon P. Mitchell. London: Taylor \& Francis, 2003. 1-15.

Winter, Ulrich. "De la memoria recuperada a la memoria performativa. Hacia una nueva semántica cultural de la memoria histórica en España a comienzos del siglo XXI." Docuficción. Enlaces entre ficción y no-ficción en la cultura española actual. Ed. Christian von Tschilschke y Dagmar Schmelzer. Frankfurt am Main/Madrid: Vervuert/Iberoamericana, 2010. 249-264.

Winter, Ulrich, “Corpus delicti. Justicia poética, justicia histórica, el giro forense y el materialismo en la novela negra posdictatorial (acerca de la serie Heredia, de Ramón Díaz Eterovic)." Descubrir el cuerpo. Ámbitos de lo corpóreo en la novela y el cine negros de Argentina, Chile y México. Ed. Sabine Schmitz, Annegret Thiem y Daniel A. Verdú Schumann. Frankfurt am Main/Madrid: Vervuert/Iberoamericana, 2017. 45-56.

Young, James E. Writing and Rewriting the Holocaust. Narrative and the Consequences of Interpretation. Bloomington et al.: Indiana University Press, 1988. 